\title{
The Effects of Experimental Intratympanic Steroid Administration on Organ of Corti Type 1 Spiral Ganglion
}

\author{
Turgay Topcuoglu ${ }^{1}$ Murat Kocyıgıt ${ }^{2}$ Erdogan Bulut ${ }^{3}$ Safiye G. Ortekın ${ }^{2}$ Mehmet Kanter ${ }^{4}$ \\ Recep Yagız ${ }^{5}$
}

${ }^{1}$ Department of Otolaryngology, Arnavutkoy State Hospital, Istanbul, Turkey

2 Department of Otolaryngology, Kanuni Sultan Süleyman Education

Address for correspondence Murat Kocyıgıt, MD, Department of Otolaryngology, Kanuni Sultan Süleyman Education and Research and Research Hospital, Istanbul, Turkey

${ }^{3}$ Department of Audiology, Faculty of Health Sciences, Balkan

Campus, Trakya University Edirne, Turkey

${ }^{4}$ Department of Histology and Embryology, Medeniyet University,

Istanbul, Turkey

${ }^{5}$ Department of Otolaryngology, Trakya University, Edirne, Turkey

Hospital, Istanbul, Turkey (e-mail: muratdr63@yahoo.com).

Int Arch Otorhinolaryngol 2018;22:171-176.

\begin{abstract}
Keywords

- intratympanic

- spiral ganglion

- guinea pig

- microscopy

- dexamethasone

Introduction It is unclear how effective is the intratympanic (IT) steroid treatment on organ of Corti type 1 spiral ganglion, its optimal dosage and frequency of administration. The effect of dexamethasone on cochlear functions in individuals with a normal hearing ability is also unknown.

Objective The aim of this study was to evaluate, at the electrophysiological and ultrastructural levels, the effect of IT dexamethasone administration in guinea pigs with normal hearing on organ of Corti type 1 spiral ganglion.

Methods A total of 20 guinea pigs ( $n=40$ ears) whose hearing was detected to be normal by electrophysiological tests were included in the study and randomly divided into 6 groups. Four groups were considered study groups, while 2 groups were considered control groups. Dexamethasone was administered intratympanically in doses of $2 \mathrm{mg} / \mathrm{mL}$ and $4 \mathrm{mg} / \mathrm{mL}$ in the guinea pigs in the study groups. The animals in the control groups received physiological saline in equal doses as the study groups. All interventions were performed under general anesthesia, and the electrophysiological tests were repeated following the IT injections.

Results No statistically significant differences were found among the groups when the IT injections were evaluated in terms of the electrophysiological measurements $(p>0.05)$. The ultrastructural evaluation showed a cellular mitochondrial increase in the spiral ganglions of the cochlea in the groups in which dexamethasone was administered in a dose of $4 \mathrm{mg} / \mathrm{mL}$.

Conclusion According to the findings of this study, it can be suggested that the IT injection of dexamethasone is safe, and when applied in a dose of $4 \mathrm{mg} / \mathrm{mL}$, it increases metabolic activity at the cellular level.
\end{abstract}

received

December 13, 2016

accepted

April 12, 2017

published online

July 14, 2017
DOI https://doi.org/

10.1055/s-0037-1604067.

ISSN $1809-9777$.
Copyright $(2018$ by Thieme Revinter

Publicações Ltda, Rio de Janeiro, Brazil
License terms

(c) (i) $\ominus$ (\$) 


\section{Introduction}

Corticosteroids are the most frequently used drugs due to their anti-inflammatory, antiallergic and immunosuppressive effects. ${ }^{1,2}$ One of the suggested mechanisms of the effect of corticosteroids administered into the vestibule of the middle ear is that they pass to the inner ear through the round window, and cause resolution of the cellular edema and metabolic disorders in the ear, as well as cellular membrane stabilization. ${ }^{3-5}$ In addition, with their sedative effects, they supposedly suppress the irritating or hypersensitive conditions of the sensorial cells of the inner ear. ${ }^{3}$

Intratympanic (IT) administration is the administration of a drug in liquid form, mainly aminoglycosides and steroids, by injection through the tympanic membrane, ${ }^{3}$ with the help of a ventilation tube, ${ }^{4}$ or trans tubal $^{5}$ or trans meatal ${ }^{6}$ catheters, into the middle ear. Through this route, the drug directly contacts the round window membrane, and passes to the inner ear by diffusion. ${ }^{7}$

The term IT steroid is generally used for glucocorticoids, and the corticosteroid used is almost invariably dexamethasone. ${ }^{8}$ Intratympanic dexamethasone resulted in higher perilymph steroid levels than intravenous dexamethasone. ${ }^{9}$ Generally, the indications for the use of IT dexamethasone in the studies performed include idiopathic acute sensorineural hearing loss; Ménière's disease; labyrinthine vertigo; and tinnitus. $^{9,10}$ It is unclear how effective is the IT steroid treatment on organ of Corti type 1 spiral ganglion, its optimal dosage and frequency of administration. ${ }^{10}$ The effect of dexamethasone on cochlear functions in individuals with normal hearing ability is also unknown.

\section{Objective}

The aim of this study was to evaluate at the electrophysiological and ultrastructural levels the effect of the administration of IT dexamethasone on organ of Corti type 1 spiral ganglion in guinea pigs with normal hearing.

\section{Methods}

\section{Animals}

All animal experiments were reviewed by the Animal Care and Use Ethics Committee of one of our institutions (approval protocol number: TÜTFEK-2007/058). A total of
20 healthy young adult (ages 4-6 months) pigmented guinea pigs (weighing between $400 \mathrm{~g}$ and $600 \mathrm{~g}$ ) with normal auropalpebral reflex were used. All animals underwent a bilateral otoscopic examination and audiologic evaluation, including $1,000 \mathrm{~Hz}$ probe-tone tympanometry, auditory brainstem response (ABR) and otoacoustic emission (OAE) tests. The tympanometric and all OAE measurements were performed using a Madsen Capella (GN Otometrics A/S, Taastrup, Denmark) OAE device. The probe assembly was fixed with an adaptor to allow a tight and deep insertion into the ear canals of the guinea pigs, and the probe was fixed in the appropriate position with a holder during the measurements. The animals were placed in a soundproof chamber. All measurements were performed under general anesthesia. The guinea pigs were anesthetized with an intramuscular (IM) injection of ketamine (40 mg/kg; Ketalar ampul, Pfizer, Istanbul, Turkey) and Xylazine (10 mg/kg; Rhompun flakon, Bayer, Istanbul, Turkey). Body temperature was maintained at $38^{\circ} \mathrm{C}$ with a warming blanket. Guinea pigs with bilateral abnormal hearing in the electrophysiological examination were excluded from the study. Only guinea pigs with normal bilateral hearing were included. A total of twenty guinea pigs ( $n=40$ ears) were randomly divided into 4 study groups (S1-S4) and 2 control groups (C1 and C2).

\section{Intratympanic Administrations}

In IT injections, dexamethasone (Dexamethasone 21-phosphate [Dekort ampul, Deva, Istanbul, Turkey]), and physiological saline ( $0.9 \% \mathrm{NaCl}$; Eczacibasi, Istanbul, Turkey) were administered to the postero-inferior quadrants of the tympanic membranes with $\sim 0.08-0.1 \mathrm{~mL}$ of volume (until the middle ear was full). The commercial formula of dexamethasone $8 \mathrm{mg} / 2 \mathrm{~mL}$ was used diluted in $1 / 2$ ratios with $0.9 \%$ $\mathrm{NaCl}$ solution. To evaluate the electrophysiological and ultrastructural effects of dexamethasone on the cochlea according to its dose and frequency of administration, dexamethasone was administered in a dose of $4 \mathrm{mg} / \mathrm{mL}$ to the S1 and S3 groups, and of $2 \mathrm{mg} / \mathrm{mL}$ to the $\mathrm{S} 2$ and S4 groups in IT injections. Physiological saline was administered in equal doses to the control groups ( $\mathrm{C} 1: 4 \mathrm{mg} / \mathrm{mL} ; \mathrm{C} 2: 2 \mathrm{mg} / \mathrm{mL}$ ). The IT injections were administered 4 times a day with 4-day intervals in between them, totaling 4 times for the S1, S2 and $\mathrm{C} 1$ groups, while the injections were administered twice daily with 2-day intervals, totaling 4 times for groups S3, S4 and C2 (-Table 1).

Table 1 Administration of intratympanic dexamethasone in the groups

\begin{tabular}{|l|l|l|l|}
\hline Group (day) & $\begin{array}{l}\text { Dexamethasone } \\
\text { (S1-S3) } 4 \mathrm{mg} / \mathrm{mL}(\mathbf{n})\end{array}$ & $\begin{array}{l}\text { Dexamethasone } \\
\text { (S2-S4) } \mathbf{~ m g / m L}(\mathbf{n})\end{array}$ & $\begin{array}{l}\text { \%0.09 NaCl } \\
(\mathrm{C} 1-\mathrm{C} 2)(\mathbf{n})\end{array}$ \\
\hline Control (a) & - & - & 4 times a day (6) \\
\hline Control (b) & - & - & 4 times a day (6) \\
\hline Study (a) & 4 times a day (7) & 4 times a day (7) & -- \\
\hline Study (b) & 4 times a day (7) & 4 times a day (7) & -- \\
\hline
\end{tabular}

Abbreviations: a, repeated every four days; b, repeated every two days; $\mathrm{C} 1$, control group 1; C2, control group 2; $\mathrm{NaCl}$, sodium chloride; S1, study group 1; S2, study group 2; S3, study group 3; S4, study group 4. 


\section{Electrophysiological Examination}

Tympanometric examination

Immitansmetric tests were performed using a Capella-Madsen pediatric OAE probe assembly (Budapest, Hungary) fitted to the ear canal. The probe tone was set at $1,000 \mathrm{~Hz}$. The pump speed was $100 \mathrm{daPa} / \mathrm{sec}$ (decapascal per second). The pressure range of the measurement was set to $+200 \mathrm{daPa}$ and $-200 \mathrm{daPa}$. Type " $A$ " tympanograms (the peak pressure was between +100 daPa and -100 daPa) were accepted as normal tympanograms.

Transient-evoked otoacoustic emission recordings

Transient-evoked otoacoustic emission (TEOAE) tests were performed in a soundproof room using a Capella-Madsen pediatric OAE probe assembly fitted to the ear canal. ${ }^{11} \mathrm{Re}-$ sponses to clicks were windowed at 2-20 milliseconds after stimulus onset, and averaged following 2,080 repeated re-

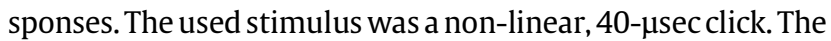
clicks were presented at a sound pressure level (SPL) of $80 \mathrm{~dB}$. In order to assess outer hair cell activation, TEOAE reproducibility data were given as the mean percentage between $750 \mathrm{~Hz}$ and $4,000 \mathrm{~Hz}$. The TEOAE responses showed that all guinea pigs had an average response rate $>70 \%$, which confirmed that outer hair cell activation was within the physiological limits. Parameters of reproducibility correlation (\%), response (emission strength) value ( $\mathrm{dB}$ SPL) and signal-noise/ratio (S/N-R, dB $\mathrm{SPL}$ ) in the TEOAE measurements were evaluated in the guinea pigs that demonstrated an intact tympanic membrane at the otoscopic and immitansmetric examinations (type A tympanogram) following the IT injections.

\section{Auditory brainstem response recordings}

The ABR responses were recorded by three silver needle electrodes (Yongsheng, China) placed subdermally over the vertex (positive), the ipsilateral mastoid (negative), and the contralateral mastoid (ground/reference) of the guinea pigs. Click stimuli were delivered through an E-A-R Tone $3 \mathrm{~A}$ (Aearo Co., Indianapolis, IN, US) insert earphone, and the ABR was recorded with a BRA2-05/95 version 5.XX (Danplex, Neckartenzlingen, Germany). The repetition rate was $10 / \mathrm{sec}$, and an average of 300 sweeps was recorded. The stimulus intensity was initially 80 decibels above normal adult hearing level ( $\mathrm{dB} \mathrm{nHL}$ ), followed by $10-\mathrm{dB}$ decrements until the waveforms were no longer present, thus determining the threshold of the ABR. The ABR threshold was defined as the lowest $\mathrm{dB} \mathrm{nHL}$ level that produced a reliable peak III in the ABR waveforms.

\section{Research Protocol}

A total of 20 ( $n=40$ ears) guinea pigs with normal bilateral hearing were included. The guinea pigs were randomly divided into six groups and treated as follows:

- Study group 1 (S1, $\boldsymbol{n}=\mathbf{7}$ ears): dexamethasone $4 \mathrm{mg} / \mathrm{mL}$, with 4-day intervals, in a total of 4 times, was administered in 7 ears;

- Study group 2 (S2, $\boldsymbol{n}=\mathbf{7}$ ears): dexamethasone $2 \mathrm{mg} / \mathrm{mL}$, with 4-day intervals, in a total of 4 times, was administered in 7 ears;
- Control group 1 (C1, $\boldsymbol{n}=\mathbf{6}$ ears): physiological saline $4 \mathrm{mg} / \mathrm{mL}$, with 4-day intervals, in a total of 4 times, was administered in 6 ears

- Study group 3 (S3, $\boldsymbol{n}=\mathbf{7}$ ears): dexamethasone $4 \mathrm{mg} / \mathrm{mL}$, with 2-day intervals, in a total of 4 times, was administered in 7 ears.

- Study group 4 (S4, $\boldsymbol{n}=\mathbf{7}$ ears): dexamethasone $2 \mathrm{mg} / \mathrm{mL}$, with 2-day intervals, in a total of 4 times, was administered in 7 ears.

- Control group 2 (C2, $\boldsymbol{n}=\mathbf{6}$ ears): physiological saline $2 \mathrm{mg} / \mathrm{mL}$, with 2-day intervals, in a total of 4 times, was administered in 6 ears.

The monitoring of the intratympanic administrations was investigated in all groups with ABR and TEOAE tests. After the completion of the electrophysiological measurements, the guinea pigs were sacrificed to remove the cochlea for the examination of the ultrastructure. Ultrastructural changes in the cochleas were examined with transmission electron microscopy (TEM).

\section{Examination of the Ultrastructure}

After decapitation, the temporal bones were stored with $2.5 \%$ glutaraldehyde in a $0.1 \mathrm{M}$ phosphate buffer for 12 hours, and then rinsed with $0.1 \mathrm{~mL} / \mathrm{L}$ phosphate buffer at $\mathrm{pH} 7.4$ for 1 day. After incubation in $0.1 \mathrm{M}$ disodium ethylenediaminetetraacetic (Na-EDTA, Sigma-Aldrich, St. Louis, MO, US) decalcifier ( $\mathrm{pH}: 7.4)$ for 3 weeks, we opened the tympanic bulla of the temporal bones, and the otic capsule of the cochlea was removed under stereo microscopy (Olympus $1 \times 71$ S8 F3, Olympus Corporation, Shinjuku, Tokio, Japan). The cochleae were post-fixed with $1 \%$ osmium tetroxide in phosphate buffer for 1 hour and then rinsed with phosphate buffer. The tissues were dehydrated through a graded series of ethanol. Subsequently, in order to define the cut-off areas of the blocks, semi-thin sections and toward basal to apex were vertically obtained with an RMC-MTX Ultramicrotome (Boeckeler Instruments, Inc., Tucson, AR, US), and stained with azure blue. Thin sections with a thickness of 40-60 nm from the determined areas were obtained and stained with uranyl acetate and Reynold's lead citrate to increase contrast. Those sections were evaluated and photographed using a transmission electron microscope (JEOL 1010, JEOL, Akishima, Tokyo, Japan).

\section{Statistical Analysis}

The statistical analysis was performed using The University Information Technology Center Minitab Packet Program (Minitab, Inc., State College, Pennsylvania, US; S0064 Minitab Release 13, license no: wep 1331, 00197). In the statistical analysis, after searching the appropriateness to normal distribution. As the data were not convenient for parametric tests, intra-group comparisons were performed using the Wilcoxon signed-rank test, whereas the comparisons among the groups were performed using the Mann-Whitney $U$ test. The Kruskal-Wallis test was applied to the comparisons among the groups for more than two groups. 
174 The Effects of Experimental Intratympanic Steroid Administration Topcuoglu et al.

\section{Results}

\section{Electrophysiology}

The ABR thresholds for the click stimulus were compared before and after the IT administration in all groups (-Table 2). For the click stimulus, there was no significant ABR threshold difference among the study groups' (MannWhitney U test, $p>0.05$ ) IT administration. Groups S1 and S2 did not have a significant difference in the ABR thresholds when compared with groups S3 and S4 (Kruskal-Wallis test, $p>0.05$ ). There was no significant difference in ABR thresholds in the control groups before and after the IT administration (Wilcoxon signed-rank test, $p>0.05$ ). In the analysis of the TEOAE measurements ( - Table 2 ), there was no significant difference among the study groups (Kruskal-Wallis test, $p>0.05$ ). There was no significant differences in the TEOAE parameters in the control groups before and after the IT administration (Wilcoxon signed-rank test $p>0.05$ ).

\section{Analysis of the Transmission Electron Microscopy}

In the present study, the organ of Corti spiral ganglion (-Fig. 1), the myelinated or unmyelinated afferent and efferent nerve fibers, and their synaptic terminals were

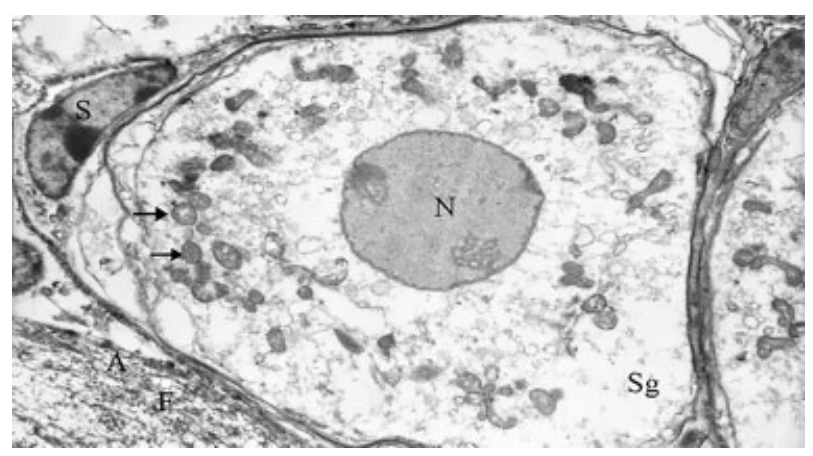

Fig. 1 Neurons of the cochlear spiral ganglion $(\mathrm{Sg})$ of a sample from $C 2$ are observed. The glial cells $(G)$ around the nerve cells can be especially observed. The nucleus $(\mathrm{N})$, the mitochondria $(\rightarrow)$, the thin neurofilaments ( $F$ ) and other organelles in the neuron and axoplasm (A) are present $\times 4,000$. found to be normal (-Fig. 2). The borders of the spiral ganglion and glial cells were observed to be normal.

When the electron microscopic findings of the S1 and S4 groups were evaluated, the spiral ganglion and the neurons and their synapses were detected. The mitochondria, cytomembranes and other organelles were present in the cytoplasm. The borders of the spiral ganglion and glial cells were seen to be normal (-Fig. 3). An increased number of mitochondria, swelling of the matrix, and of the cytoplasm of the nerve cells were observed (-Fig. 4 ).

\section{Discussion}

Intratympanic steroid treatment has been recently popularized in the medical treatment of cochlear diseases. ${ }^{12}$ The mechanism of the effect of the steroids in the inner ear has not yet been completely understood. The metabolism of the steroids, when compared with other organs, differs in cochlear tissues, including in the uptake and elimination. ${ }^{13}$ Intratympanic application provides higher steroid concentrations in the inner ear compared with intravenous or oral applications.

Although the reported complications are very rare secondary to the drug administered in the IT treatment,

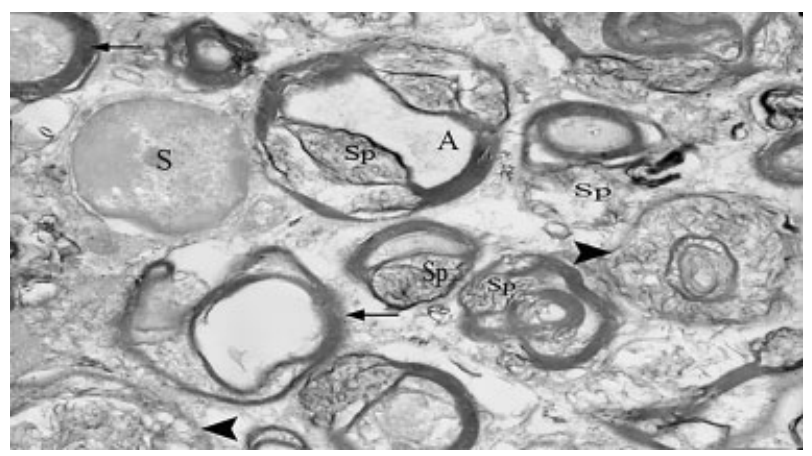

Fig. 2 View of a sample of the cochlear spiral ganglion that belongs to $\mathrm{C} 1$, one of the control groups. Many afferent and efferent myelinated $(\rightarrow)$ and unmyelinated $(\rightarrow)$ nerves and axoaxonal or axodendritic terminals and synapses (Sp) are seen. A glial (G) cell is seen next to the axon $\times 6,000$.

Table 2 Auditory brainstem and transient evoked otoacoustic emission responses before and after the intratympanic injections in the groups

\begin{tabular}{|l|l|l|l|l|l|l|l|l|}
\hline \multirow{3}{*}{ Groups } & \multicolumn{2}{|l|}{ TEOAE } & \multicolumn{2}{l|}{$\begin{array}{l}\text { Response } \\
\text { (dB SPL) }\end{array}$} \\
\cline { 2 - 8 } & $\begin{array}{l}\text { Reproductubility } \\
\text { (\%) }\end{array}$ & preT & postT & preT & \multicolumn{2}{l|}{$\begin{array}{l}\text { S/N-R } \\
\text { (dB SPL) }\end{array}$} \\
\cline { 2 - 9 } & postT & preT & postT & \multicolumn{2}{l|}{ preT } & postT \\
\hline S1 & $91.2 \pm 5.1$ & $90.5 \pm 5.1$ & $23.4 \pm 3.5$ & $20.2 \pm 5.3$ & $11.2 \pm 3.1$ & $12.9 \pm 2.7$ & 10 & 10 \\
\hline S2 & $90.5 \pm 6.5$ & $93.4 \pm 6.1$ & $23.1 \pm 4.2$ & $25.7 \pm 2.4$ & $11.7 \pm 3.7$ & $13.7 \pm 3.5$ & 10 & 10 \\
\hline S3 & $92.6 \pm 5.7$ & $90.6 \pm 5.1$ & $24.7 \pm 4.5$ & $22.4 \pm 5.1$ & $14.5 \pm 3.2$ & $12.7 \pm 4.1$ & 10 & 10 \\
\hline S4 & $92.3 \pm 4.2$ & $91.6 \pm 3.9$ & $21.5 \pm 4.0$ & $21.5 \pm 5.6$ & $14.0 \pm 3.1$ & $9.8 \pm 4.4$ & 10 & 10 \\
\hline C1 & $95.3 \pm 3.3$ & $89.0 \pm 6.1$ & $26.1 \pm 1.8$ & $22.7 \pm 4.2$ & $16.6 \pm 4.5$ & $11.3 \pm 3.3$ & 10 & 10 \\
\hline C2 & $87.6 \pm 9.1$ & $91.4 \pm 11$ & $19.3 \pm 7.4$ & $22.4 \pm 10$ & $11.5 \pm 3.9$ & $11.6 \pm 4.3$ & 10 & 10 \\
\hline
\end{tabular}

Abbreviations: ABR, auditory brainstem response; $\mathrm{dB}$ SPL, decibel sound pressure level; $\mathrm{dB} \mathrm{nHL}$, decibel above normal adult hearing level; postT, post-treatment; preT, pretreatment, S/N-R, signal/noise ratio; TEOAE, transient-evoked otoacoustic emissions. 


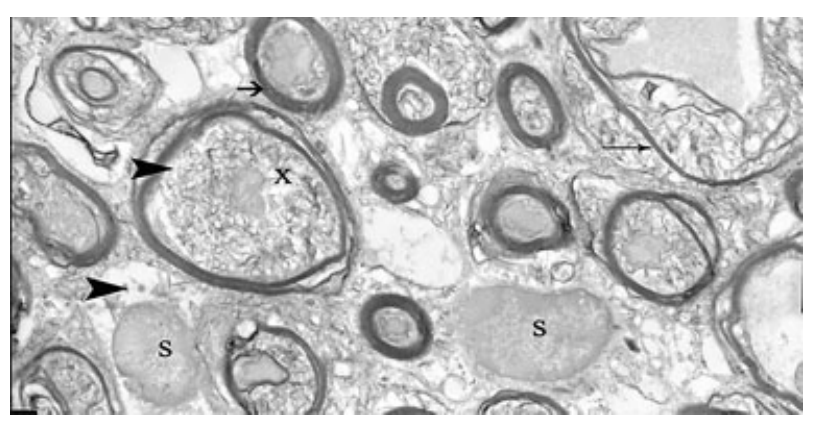

Fig. 3 View of a sample of the cochlear spiral ganglion that belongs to S2, one of the study groups. Many myelinated $(\rightarrow)$, unmyelinated $(\rightarrow)$ nerves and their terminals are observed. Synaptic acetylcholine granules are seen in the glial cells $(G)$ and in and out $(\rightarrow)$ of the synapses $(\mathrm{Sp}) \times 5,000$.

complications related mostly to the route of administration have been reported. Among these, permanent perforation, short-term attack of otitis media that was easily controlled with antibiotics, and hearing loss in a significant level can be mentioned in patients in whom a tube was inserted. ${ }^{14,15}$ When the clinical studies related to the use of IT dexamethasone in the literature are evaluated, we can see that it is used in general in diseases that cause an impairment of cochlear function, such as idiopathic sudden sensorineural hearing loss, Ménière's disease and tinnitus; however, there is no consensus on the dose and frequency of use of dexamethasone. ${ }^{16,17}$

Yilmaz et $\mathrm{al}^{17}$, in their study of 26 patients with tinnitus, administered IT dexamethasone $(4 \mathrm{mg} / \mathrm{mL}) 5$ times with 2 day intervals in between. They reported no change in the auditory functions and reproducibility of the patients after the injections; however, they reported a significant increase in the TEOAE reproducibility values. The authors suggested that this supported the finding that IT dexamethasone has no negative effect on the functions of outer hair cells evaluated by OAE; however, they concluded that the effect of the IT administrations on OHC (outer hair cells) should be assessed with different drugs as well.

In the present study, we found that IT dexamethasone administered in different doses ( $2 \mathrm{mg} / \mathrm{mL}$ and $4 \mathrm{mg} / \mathrm{mL}$ ) and with different durations (4 times with 2-day and 4-day intervals) in the ears of healthy guinea pigs exerted no statistically significant negative change in the TEOAEs, which is accepted as a marker of cochlear OHC function. In addition, no significant change was detected in the TEOAEs' following the injections in the control groups, in which physiological saline was administered. In light of the OAE findings obtained from the control groups in this study, it can be suggested that IT administration is safe and has no negative effect on the cochlear functions that originates from the administration itself.

Ugur et al $^{18}$ administered IT dexamethasone in a dose of $4 \mathrm{mg} / \mathrm{mL}$ for 5 days in guinea pigs, and found no significant changes in the auditory functions and histological findings compared with the group that received physiological saline. The findings of that study are similar to the findings of the present study.

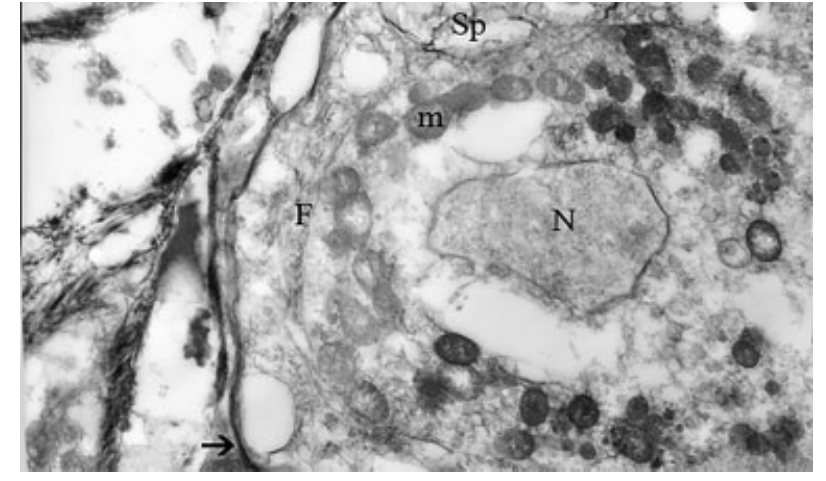

Fig. 4 View of a nerve that belongs to $\mathrm{S} 4$. Many mitochondria ( $\mathrm{m}$ ) are seen in the cytoplasm. The nucleus $(N)$, the neurofibrills $(f)$, the synaptic terminal $(\mathrm{Sp})$, the cell membrane $(\rightarrow) \times 5,000$.

Shirwany et al $^{19}$ demonstrated that the cochlear blood flow was increased at least an hour after the IT dexamethasone injection in guinea pigs compared with the baseline; however, they detected no histological change in light microscopic findings. They found no change in the ABRs either. In the present study, on the other hand, no change was detected in the ABR thresholds following the injections in the study groups in which IT dexamethasone was administered in doses of $4 \mathrm{mg} / \mathrm{mL}$ and $2 \mathrm{mg} / \mathrm{mL}$ at different intervals (2 days and 4 days). The electron microscopic evaluation in the present study revealed a normal spiral ganglion and glial cells of the cochlea, and normal nerves and synapses following the dexamethasone injection in a dose of $2 \mathrm{mg} / \mathrm{mL}$ in $\mathrm{S} 2$ and S4; however, a proliferation of mitochondria in the neurons of the spiral ganglion was observed following the dexamethasone injection in a dose of $4 \mathrm{mg} / \mathrm{mL}$ in S1 and S4.

In light of the electron microscopic findings of the present study, the administration of IT dexamethasone has no negative effect on the cochlear structures of the ears of healthy guinea pigs. Similar cochlear findings were obtained in the control groups, who received physiological saline. Additionally, when the electron microscopic findings of the study groups were evaluated, we observed that, although the normal cochlear structure was preserved in the study groups who received dexamethasone in a dose of $4 \mathrm{mg} / \mathrm{mL}$ ( $\mathrm{S} 1$ and S4). However, findings supporting an increase in metabolic activity characterized by mitochondrial changes and findings that were not related to the TEOAE parameters were observed.

\section{Conclusion}

With the findings of the present study, it can be suggested that the administration of IT dexamethasone has no negative effect on the healthy guinea pig ears, and that when administered in a dose of $4 \mathrm{mg} / \mathrm{mL}$, it increases cellular metabolic activity.

Conflicts of Interest

The authors have no conflicts of interest to declare. 
Research Involving Human Participants and/or Animals All procedures performed in studies involving human participants and/or animals were in accordance with the ethical standards of the institutional and/or national research committee, and with the 1964 Helsinki declaration and its subsequent amendments or comparable ethical standards.

\section{References}

1 Schimer BP, Parker KL. Adrenocorticotropic Hormone Adrenocortical Steroids and Their Synthetic Analogs; Inhibitors of the Synthesis and Actions of Adrenocortical Hormones. In: Hardman JG, Gilman AG, Limbird LE (Eds). The Pharmacological Basis of Therapeutics. 9th ed. New York: McGraw-Hill companies; 1996:1459-85

2 Chrousos GP, Margioris AN. Adrenocorticosteroids \& Adrenocortical Antagonists. In: Katzung BG (Ed). Basics and Clinical Pharmacology. 8th ed. San Francisco: McGraw-Hill companies; 2001:660-78

3 Itoh A, Sakata E. Treatment of vestibular disorders. Acta Otolaryngol Suppl 1991;481:617-623

4 Sennaroglu L, Sennaroglu G, Gursel B, Dini FM. Intratympanic dexamethasone, intratympanic gentamicin, and endolymphatic sac surgery for intractable vertigo in Meniere's disease. Otolaryngol Head Neck Surg 2001;125(05):537-543

5 Yamazaki T, Hayashi M, Komatsuzaki A. Intratympanic gentamicin therapy for Menière's disease placed by a tubal catheter with systematic isosorbide. Acta Otolaryngol Suppl 1991;481:613-616

6 Nedzelski JM, Schessel DA, Bryce GE, Pfleiderer AG. Chemical labyrinthectomy: local application of gentamicin for the treatment of unilateral Menière's disease. Am J Otol 1992;13(01):18-22

7 McFeely WJ, Singleton GT, Rodriguez FJ, Antonelli PJ. Intratympanic gentamicin treatment for Meniere's disease. Otolaryngol Head Neck Surg 1998;118(05):589-596
8 Yılmaz İ, Akkuzu B, Özlüoğlu LN. İntratimpanik uygulamalar popüler bir yöntem üzerine derleme. Otoskop. 2003;3:145-155

9 Chandrasekhar SS, Rubinstein RY, Kwartler JA, et al. Dexamethasone pharmacokinetics in the inner ear: comparison of route of administration and use of facilitating agents. Otolaryngol Head Neck Surg 2000;122(04):521-528

10 Alles MJRC, der Gaag MA, Stokroos RJ. Intratympanic steroid therapy for inner ear diseases, a review of the literature. Eur Arch Otorhinolaryngol 2006;263(09):791-797

11 Uzun C, Yağız R, Koten M, Adalı MK, Karasalihoğlu AR. Kobaylarda transient evoked otoakustik emisyon ölçüm yöntemi. Kulak Burun Bogaz Ihtis Derg 2000;7:97-105

12 Ceylan K, Ünlü İ, Samim E. İntratimpanik steroid tedavisi. Otoscope. 2004;3:108-115

13 Lalwani AK, McGuire JF. Koklea ve labirentin farmakolojik tedavisi (çeviri: S. Yetişer). Koç C (Editör). Cummings Otolaringoloji Baş ve Boyun Cerrahisi cilt 4, Ankara: Güneş Tıp Kitabevleri; 2007: s.2944-76

14 Parnes LS, Sun AH, Freeman DJ. Corticosteroid pharmacokinetics in the inner ear fluids: an animal study followed by clinical application. Laryngoscope 1999;109(7 Pt 2):1-17

15 Barrs DM, Keyser JS, Stallworth C, McElveen JT Jr. Intratympanic steroid injections for intractable Ménière's disease. Laryngoscope 2001;111(12):2100-2104

16 Araújo MF, Oliveira CA, Bahmad FM Jr. Intratympanic dexamethasone injections as a treatment for severe, disabling tinnitus: does it work? Arch Otolaryngol Head Neck Surg 2005;131(02):113-117

17 Yilmaz I, Yilmazer C, Erkan AN, Aslan SG, Ozluoglu LN. Intratympanic dexamethasone injection effects on transient-evoked otoacoustic emission. Am J Otolaryngol 2005;26(02):113-117

18 Uğur MZ, Önal HK, Akdağ H, Arslanoğlu S, Gökçe AH, Etit D. İntratimpanik deksametazonun guinea piglerinde işitme eşikleri ve koklea histopatolojisi üzerine etkisi. KBB Postası. 2007;1:4-8

19 Shirwany NA, Seidman MD, Tang W. Effect of transtympanic injection of steroids on cochlear blood flow, auditory sensitivity, and histology in the guinea pig. Am J Otol 1998;19(02):230-235 